\title{
Kepemimpinan yang Mampu Mewujudkan Visi menjadi Realitas: Studi Kasus Tim Musik GKI Gejayan Yogyakarta
}

\author{
Iwan Setiawan Dani \\ Program Pascasarjana Institut Seni Indonesia Yogyakarta \\ email: iwan.dani285@gmail.com
}

\begin{abstract}
Abstrak
Topik "kepemimpinan" adalah topik riset fenomena sosial yang paling komprehensif karena kepemimpinan dianggap sebagai faktor penentu keberhasilan organisasi apapun, baik organisasi profit maupun nonprofit. Fenomena sosial yang menjadi objek penelitian ini adalah sebuah organisasi nonprofit/keagamaan: Gereja Kristen Indonesia (GKI) Gejayan Yogyakarta. Gereja yang berdiri tahun 2000 dengan jumlah jemaat awal hanya 200 orang, telah berkembang menjadi gereja yang dihadiri 6.000 orang jemaat tiap minggunya dan mengadakan 10 kali ibadah minggu dari yang semula hanya 2 kali saja. Setiap minggu tidak kurang dari 300 orang volunteer/sukarelawan terlibat dalam pelayanan ibadah. Tujuan penelitian adalah untuk mengetahui model kepemimpinan di GKI Gejayan yang dihasilkan untuk mewujudkan visinya. Metode penelitian yang digunakan adalah kualitatif deskriptif. Data diperoleh dari wawancara mendalam dengan 9 narasumber yang terlibat langsung. Temuan penelitian ini adalah: model kepemimpinan di GKI Gejayan adalah model kepemimpinan yang hadir (attending leadership). Temuan lainnya adalah motivasi para aktivis terdiri dari Spiritual Motivation dan Extrinsic Motivation.
\end{abstract}

Kata kunci: kepemimpinan, kepemimpinan transformatif, manajemen musik gereja, voluteerism, motivasi

\begin{abstract}
The topic of "leadership" is the most comprehensive topic of research on social phenomena because leadership is seen as a determining factor for the success of any organization, both profit and non-profit organizations. The social phenomenon which become the object of this research is a non-profit/religious organization: the Indonesian Christian Church (GKI) Gejayan Yogyakarta. The church, which was founded in 2000 with an initial number of congregations of only 200 people, has developed into a church that is attended by 6.000 congregations each week and holds 10 times the worship of the original week only two times. Every week no less than 300 volunteers are involved in worship services. The aim of the study was to find out the leadership model of GKI Gejayan which resulted in realizing its vision. The research method used is descriptive qualitative. Data were obtained from indepth interviews with 9 resource persons who were directly involved. The findings of this study are: the leadership model at GKI Gejayan is an Attending Leadership model. Another finding is the motivation of activists consisting of Spiritual Motivation and Extrinsic Motivation.
\end{abstract}

Keywords: leadership, transformational leadership, church music management, volunteer, volunteerism, motivation 


\section{PENDAHULUAN}

\section{Tentang GKI Gejayan}

Pertumbuhan jemaat dan jumlah ibadah yang diselenggarakan oleh GKI Gejayan yang terletak di Jl. Jembatan Merah No. 84 D, Prayan Kulon Gejayan Yogyakarta - menjadi fenomena yang menarik untuk diteliti. Gereja yang berdiri tanggal 3 Maret 2000 dengan hanya 206 orang jemaat mula-mula dan jumlah ibadah hanya dua kali, kini telah berevolusi menjadi gereja dengan 6.000 umat yang hadir tiap minggunya dan melayani 10 kali ibadah. Penelitian ini berusaha mencari jawaban bagaimana evolusi itu terjadi melalui pendekatan model kepemimpinan dan manajemen volunteer/relawan khusunya yang terlibat dalam peribadahan di GKI Gejayan.

Pertama-tama yang harus saya ungkapkan bahwa GKI Gejayan memiliki kekhasan yakni lokasinya sangat dekat dengan universitas besar seperti: UGM, UNY, Universitas Sanata Dharma, dan Universitas Atma Jaya sehingga menjadikannya sebagai gereja favorit para mahasiswa pendatang. Antara 60-70 persen jemaat yang hadir beribadah adalah anakanak muda yang berstatus pelajar.

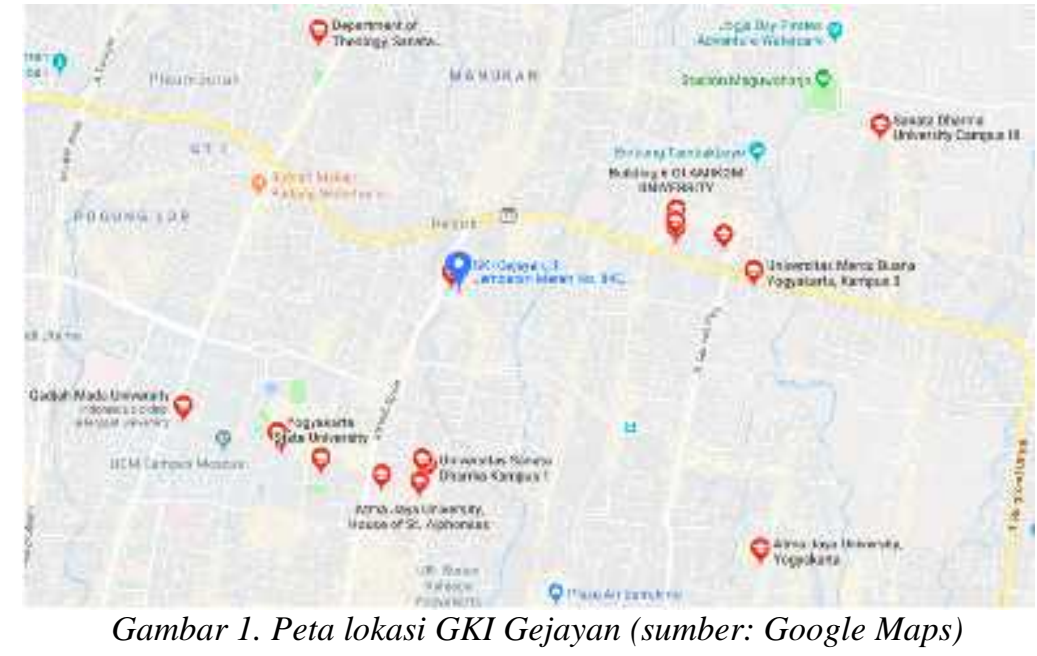

Respons dan adaptasi yang dilakukan GKI Gejayan atas given condition adalah dengan membuka diri dan mendeklarasikan sebagai gereja yang terbuka. Pendeta Paulus Lie mengatakan bahwa eklesiologi GKI Gejayan adalah gereja terbuka dan ini ditegaskan melalui visinya:

"GKI Gejayan adalah rumah kita bersama, tempat semua kita diterima, dan hidup bersama sebagai satu keluarga. Tempat untuk berbagi dan bercerita suka dan duka, saling menghibur dan membangun dalam kebersamaan, ibadah dan pengajaran. Dalam keluarga ini, kita saling menerima tanpa membeda-bedakan latar belakang suku, asal daerah, asal gereja, dan perbedaan lainnya." (https://gkigejayan.or.id)

Konsekuensi dari pilihannya sebagai gereja terbuka, GKI Gejayan melakukan perubahan-perubahan seperti: merancang berbagai bentuk ibadah yang sesuai dengan kebutuhan jemaat, menyediakan layanan bagi para mahasiswa, baik yang terkait kebutuhan 
rohani (iman) mereka maupun kebutuhan lainnya seperti pos kesehatan, konsultasi studi, olah raga, dan kegiatan kreativitas lainnya.

\section{Pengembangan Bentuk Ibadah yang Variatif}

Pengembangan bentuk ibadah yang variatif adalah salah satu respons perubahan GKI Gejayan menjadi gereja terbuka. Bentuk ibadah berdasarkan karakter musik pengiring ibadah. Ibadah inovatif karakter musiknya adalah akustik yang light and soft cocok untuk ibadah keluarga. Ibadah Umum karakter musiknya adalah standar himne, cocok untuk jemaat yang konservatif. Ibadah ekspresif musiknya full band dan lagi-lagunya adalah lagu rohani Kristen kontemporer, cocok buat kalangan muda. Dan yang terakhir adalah ibadah impresif dengan musik orkestra, cocok bagi jemaat penggemar musik klasik.

Untuk mencapai 10 kali ibadah, perkembangannya adalah sebagai berikut:

Tabel 1. Lini Waktu Perkembangan Jumlah Ibadah di GKI Gejayan

\begin{tabular}{|c|c|c|}
\hline Waktu & Keterangan & Jumlah Ibadah \\
\hline Maret 2000 & $\begin{array}{l}\text { Untuk pertama kali } \\
\text { GKI Gejayan berdiri }\end{array}$ & $\begin{array}{c}2 \text { kali ibadah umum } \\
\text { (jam tidak diketahui, tidak ada data) }\end{array}$ \\
\hline Juni 2002 & $\begin{array}{l}\text { Tambahan ibadah } \\
\text { umum di hari Sabtu } \\
\text { dan Minggu }\end{array}$ & $\begin{array}{c}5 \text { kali ibadah: Sabtu jam 17.00 (Umum), } \\
\text { Minggu jam 06.30, 09.00, 11.00, } 16.30 \text { (Umum) }\end{array}$ \\
\hline $\begin{array}{l}\text { November } \\
2003\end{array}$ & $\begin{array}{l}\text { Tambahan ibadah } \\
\text { umum }\end{array}$ & $\begin{array}{c}6 \text { kali ibadah: Sabtu jam } 17.00 \text { (Umum), } \\
\text { Minggu jam 06.30, 09.00, 11.00, 16.00, } 18.30\end{array}$ \\
\hline $\begin{array}{l}\text { November } \\
2004\end{array}$ & $\begin{array}{c}\text { Mulai ada } \\
\text { pembentukan ibadah } \\
\text { Ekspresif dan } \\
\text { Impresif }\end{array}$ & $\begin{array}{c}6 \text { kali ibadah: Sabtu jam 17.00, } \\
\text { Minggu jam 06.30, } 09.00 \text { (Umum), } 11.00 \\
\text { (Ekspresif), } 16.00 \text { (Umum), } 18.30 \text { (Impresif) }\end{array}$ \\
\hline Mei 2005 & $\begin{array}{l}\text { Perubahan ibadah hari } \\
\text { Sabtu menjadi ibadah } \\
\text { Inovatif }\end{array}$ & $\begin{array}{l}6 \text { kali ibadah: Sabtu jam } 17.00 \text { - Inovatif, } \\
\text { Minggu jam 06.30, } 09.00 \text { (Umum), } 11.00 \\
\text { (Ekspresif), } 16.00 \text { (Umum), } 18.30 \text { (Impresif) }\end{array}$ \\
\hline Maret 2007 & $\begin{array}{l}\text { Perubahan jam ibadah } \\
\text { umum dan tambahan } \\
1 \text { kali ibadah impresif }\end{array}$ & $\begin{array}{l}7 \text { kali ibadah: Sabtu jam } 17.00 \text { - inovatif, } \\
\text { Minggu jam 06.00, 08.00, } 10.00 \text { (Umum), } 12.00 \\
\text { (Ekspresif), 16.00, } 18.30 \text { (Impresif) }\end{array}$ \\
\hline $\begin{array}{l}\text { Agustus } \\
2018\end{array}$ & $\begin{array}{l}\text { Penambahan ruang } \\
\text { ibadah di The Grace } \\
\text { @Hartono Mall }\end{array}$ & $\begin{array}{c}9 \text { kali ibadah: } \\
\text { Sabtu jam 17.00 - inovatif, Minggu 06.00, } \\
\text { 08.00, 10.00 (Umum), } 12.00 \text { (Ekspresif), 16.00, } \\
18.30 \text { (Impresif) } \\
\text { The Grace Minggu 08.30 - Harmony, } 17.00 \text { - } \\
\text { Joyfull }\end{array}$ \\
\hline $\begin{array}{c}\text { Februari } \\
2019\end{array}$ & $\begin{array}{l}\text { Penambahan } 1 \text { kali } \\
\text { ibadah di The Grace } \\
\text { @Hartono Mall }\end{array}$ & $\begin{array}{c}9 \text { kali ibadah: } \\
\text { Sabtu jam 17.00 - inovatif, Minggu 06.00, } \\
\text { 08.00, } 10.00 \text { (Umum), } 12.00 \text { (Ekspresif), 16.00, } \\
18.30 \text { (Impresif) } \\
\text { The Grace Minggu 08.30 (Harmony), 16.00, } \\
18.30 \text { (Joyfull) }\end{array}$ \\
\hline
\end{tabular}

Sumber: data internal GKI Gejayan 
Dampak dari perubahan ibadah ini adalah peningkatan jumlah jemaat yang hadir di dalam ibadah secara signifikan dan secara konsisten segmen mahasiswa tetap menjadi segmen terbesar dari jemaat yang hadir beribadah.

\section{Grafik 1. Jumlah Rata-rata Jemaat yang Beribadah di GKI Gejayan}

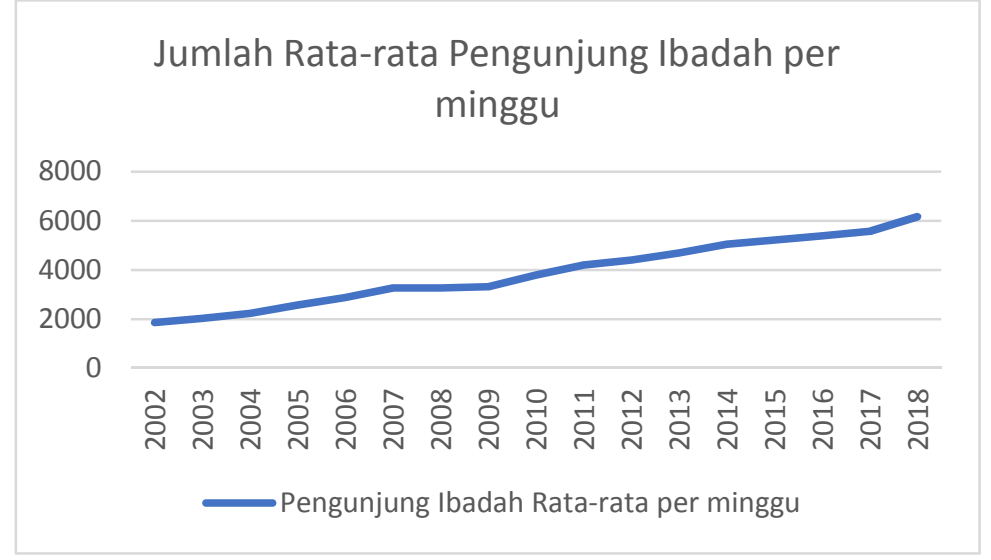

\section{Pertanyaan Penelitian}

Mewujudkan visi menjadi kenyataan adalah tujuan setiap organisasi. Bahkan bisa dikatakan bahwa alasan eksistensi sebuah organisasi adalah mewujudkan visi tersebut. Di dalam lingkup manajemen strategi disebutkan bahwa visi adalah untuk menjawab pertanyaan, "Hendak menjadi apakah organisasi kita?" ("What do we want to become?") (David dan David, 2017). Studi tentang kepemimpinan dan manajemen di dalam sebuah organisasi bermuara pada keberhasilan organisasi itu dalam mencapai target, sasaran, dan visinya.

Keberhasilan GKI Gejayan untuk mewujudkan visinya menjadi gereja yang terbuka dan bagaimana menggerakkan jemaatnya untuk berubah dan mau menerima keterbukaan adalah fenomena sosial yang menarik untuk diteliti. Muncul dua pertanyaan untuk ditemukan jawabannya dalam penelitian ini:

1. Dengan model kepemimpinan manakah GKI Gejayan mewujudkan visinya menghadirkan ibadah yang sesuai dengan kebutuhan jemaat?

2. Bagaimana mengelola tim pemusik yang notabene adalah para aktivis dan volunteer/sukarelawan agar motivasi mereka tetap terpelihara dan setia melayani?

\section{Tujuan Penelitian}

Tujuan dari penelitian ini adalah: pertama, untuk memberikan kepada kita pengetahuan kita tentang model kepemimpinan yang sukses dalam mewujudkan visinya. Meskipun organisasi yang diteliti adalah organisasi keagamaan (gereja) tidak berarti pengetahuan yang dihasilkan oleh penelitian ini tidak bisa diterapkan di organisasi nonkeagamaan. Ada nilai-nilai universal yang bisa kita petik dan kita pelajari dari model kepemimpinan ini.

Kedua, melalui penelitian ini pengetahuan kita tentang cara mengelola volunteer/sukarelawan khususnya para pemusik yang menjadi volunteer dapat bertambah. 


\section{Landasan Teori}

\section{Teori Kepemimpinan}

Topik "kepemimpinan" adalah topik riset fenomena sosial yang paling komprehensif. Alasannya adalah karena keberhasilan dan kesuksesan setiap organisasi entah itu perusahaan atau organisasi nirlaba bergantung pada tuntunan dan pimpinan para pemimpinnya (Barrow, 1977). Namun, kepemimpinan adalah sebuah konsep yang rumit. Dia tidak bisa dijelaskan dengan singkat, bahkan definisi mengenai kepemimpinan cenderung melebar (Barrow, 1977).

Dalam artikel ini penulis mencoba memahami kepemimpinan melalui tugas dari seorang pemimpin. Gardner merumuskan tugas seorang pemimpin sebagai berikut (Gardner, 1990):

- Menetapkan visi dan sasaran.

Pemimpin menetapkan sasaran dan mendorong para pengikutnya untuk bergerak ke sana. Kotter mengatakan bahwa pemimpin menetapkan arah, para manajer membuat perencanaan (Kotter, 2001).

- Menegaskan Nilai-nilai.

Pemimpin perlu secara konsisten mengingatkan para anggotanya mengenai nilai-nilai yang mereka anut yang menyebabkan mereka terikat sebagai komunitas.

- Memotivasi.

Pemimpin tidak menciptakan motivasi namun, mereka membuka dan mengarahkan motivasi yang sudah ada di dalam diri anggotanya. Kotter memberi penegasan atas bedanya memotivasi yang adalah tugas pemimpin dan mengontrol yang adalah tugas manajer (Kotter, 2001).

- Mengelola.

Seorang pemimpin dituntut untuk memiliki keterampilan manajerial seperti: membuat perencanaan, mengorganisasi institusi, menjaga agar sistem tetap berfungsi, membuat keputusan, memberlakukan keputusan politik. Terkait dengan hal ini, Kotter mengatakan bahwa kepemimpinan (leadership) dan mengelola (management) adalah dua hal yang berbeda namun tak dapat dipisahkan seperti dua sisi mata uang. Mereka saling melengkapi dalam memajukan institusi (Kotter, 2001).

- Mewujudkan persatuan yang dapat bekerja.

Tugas pemimpin untuk menjaga persatuan di tengah heterogenitas anggotanya agar tercipta persatuan yang efektif.

- Menjelaskan.

Seorang pemimpin bertugas memberi penjelasan, baik kepada kalangan internal maupun kepada kalangan eksternal/publik. Tugas ini disebut sebagai "public duties" oleh King (King et al, 2011).

- Berperan sebagai Simbol.

Menjadi seorang pemimpin berarti siap jika dirinya dijadikan simbol dari institusi yang dia pimpin. Pemimpin besar bahkan menjadi simbol yang abadi, misalnya Soekarno dikenal sebagai simbol pendiri negara Indonesia. Tuntutan ini oleh King disebut tuntutan "visibility". 
- Merepresentasikan Kelompok/Institusi.

Menjadi pemimpin berarti harus berperan menjadi representasi institusi ketika berhadapan dengan pihak luar untuk segala urusan, entah itu bernegosiasi, membangun kerja sama, dll. - Melakukan Pembaruan.

Seorang pemimpin berkewajiban menyemai sebuah pembaruan agar organisasi yang dia pimpin siap menghadapi perubahan.

Karena kepemimpinan pada intinya adalah tentang memberi pengaruh, maka penulis merasa perlu mengangkat tawaran Bernard M. Bass tentang "Kepemimpinan Transformatif" (Bass, 1990). Bass membuat garis tegas untuk membedakan antara "Kepemimpinan Transaksional" dan "Kepemimpinan Transformatif". Kebanyakan organisasi dan perusahaan yang dijumpai Bass menerapkan kepemimpinan transaksional. Di dalam kepemimpinan transaksional hubungan antara anggota/karyawan dengan para pimpinannya tak lebih dari sekedar transaksi reward and punishment (hadiah dan hukuman). Bekerjalah dengan baik maka kamu akan mendapat hadiah/imbalan, dan sebaliknya jika kamu bekerja buruk maka akan ada hukuman yang menanti.

Kepemimpinan transformatif terjadi ketika pemimpin memperluas dan meningkatkan perhatian karyawan/anggotanya, ketika si pemimpin menyentuh kebutuhan emosional karyawan/anggotanya secara pribadi. Lebih lanjut Bass menguraikan ciri-ciri Pemimpin Transformatif:

- Kharisma: menetapkan visi misi, menanamkan kebanggaan, menuai rasa hormat dan kepercayaan.

- Inspirasi: mengomunikasikan ekspektasi yang luhur, menggunakan simbol-simbol untuk memfokuskan usaha, menjelaskan tujuan yang penting dengan cara yang sederhana.

- Stimulasi intelektual: menjunjung inteligensi, rasionalitas, dan penyelesaian masalah yang hati-hati.

- Perhatian pada individu: memberi perhatian secara personal, memperlakukan anggota secara individu, melatih, dan memberi nasihat.

Jika mengacu pada Burke, maka kepemimpinan transformatif menggunakan kekuasaan untuk memengaruhi melalui kekuasaan Referent (Referent Power) (Burke, 2014, hlm.100).

\section{Teori Motivasi}

Ada dua kelompok besar penelitian tentang motivasi. Kelompok pertama adalah penelitian tentang motivasi karyawan di tempat kerja. Tujuan penelitian biasanya untuk memahami bagaimana manajemen perusahaan bisa meningkatkan kinerja karyawan melalui pemahaman apa yang memotivasi para karyawan sehingga mereka lebih produktif. Contohnya adalah penelitian Frederick Herzberg yang menghasilkan "Motivation and Hygiene Theory" (Burke dan Barron, 2014, hlm. 270-271) atau Victor H. Vroom yang memperkenalkan "Expectancy Theory" (Lunenberg, 2011) atau bahkan Maslow dengan teori "Piramida Kebutuhan" (Maslow, 1954). 
Kelompok kedua adalah penelitian tentang motivasi di kalangan para volunteer/relawan. Motivasi seorang karyawan yang bekerja di sebuah perusahaan bisa sangat berbeda dengan motivasinya ketika dia menjadi volunteer di lembaga sosial atau keagamaan. Ada dua teori penting di bidang ini: pertama adalah SDT "Self-Determination Theory" yang dikembangkan Deci dan Ryan (1985) dan kedua "Volunteer Functions Inventory” yang digagas oleh Clary, Snyder, dan Ridge pada tahun 1992 (Chacón et.al, 2017).

Teori SDT mengatakan bahwa ada dua jenis motivasi yang menggerakan para volunteer:

1. Motivasi intrinsic, yakni motivasi yang berasal dari sebuah kesadaran diri untuk mencari tantangan dalam hidup, mengembangkan kapasitasnya, dan mengeksplorasi lingkungan. Untuk motivasi ini tidak diperlukan reward atau penghargaan karena volunteer dengan motivasi ini menemukan "joy" saat mengerjakannya.

2. Motivasi extrinsic, yakni motivasi yang muncul karena adanya suatu harapan untuk mendapatkan sesuatu sebagai akibat tindakan yang dilakukannya. Untuk motivasi ini perlu suatu "pahala" atau pamrih meskipun bukan dalam benda berwujud seperti uang, tapi bisa berupa pujian atau rasa nyaman.

Teori "Volunteer Functions Inventory" (VFI) membagi motivasi ke dalam enam fungsi (Clary et. al, 1998):

1. Values (Nilai), yakni motivasi yang mengacu pada nilai ketulusan (altruistic) dan rasa kemanusiaan, keinginan untuk menolong sesama.

2. Understanding (Pemahaman), yakni motivasi yang ingin mendapatkan pengetahuan baru dan ingin mendapat pengalaman baru berdasar pengetahuannya.

3. Social (Sosial), yakni motivasi yang muncul karena rasa ingin memiliki relasi dan berteman dengan yang lain.

4. Career (Karier), yakni motivasi karena ingin meningkatkan karier dalam pekerjaan mereka atau kemampuan akademik jika volunteer seorang mahasiswa.

5. Protective (Perlindungan), yaitu kegiatan volunteer sebagai tempat dia berlindung dari problem pribadi seperti rasa kesepian (loneliness) atau rasa bersalah (guilty).

6. Enhancement (Pengembangan Diri), adalah motivasi berbasis ego untuk meningkatkan harga diri menjadi pribadi yang lebih baik seperti menjadi orang yang dianggap berjasa atau paling dibutuhkan ('untung ada saya').

\section{METODE}

\section{Metode Pengumpulan data}

Penelitian ini dilaksanakan dengan menggunakan metode penelitian kualitatif. Sumber data diperoleh dari wawancara yang dilakukan terhadap narasumber yang merupakan tokoh kunci yang terlibat langsung dalam penyusunan visi, penerjemahannya dalam program, dan pelaksanaannya di lapangan. Para narasumber ini adalah: 


\begin{tabular}{|c|l|l|l|c|}
\hline Kode & Nama & Jabatan di GKI Gejayan & Asal Daerah & $\begin{array}{c}\text { Umur } \\
\text { (per 2019) }\end{array}$ \\
\hline PL & Paulus Lie & Pendeta Jemaat & Yogyakarta & 54 \\
HS & Hana Sri Mudjiah & Pembina Tim Musik & Yogyakarta & 59 \\
RN & Ricky Nelson & Ekspresif & Sumatra Utara & 47 \\
AG & Nadeak & Penatua, Ketua Bidang I & Pontianak & 34 \\
LMS & Angga & Pembina Musik & Medan & 29 \\
YO & Lothar M. Silalahi & Ketua Komisi Musik & Sorong & 23 \\
OD & Yonias Oni & Ketua Tim KBU & Palangkaraya & 29 \\
YS & Kilikili & Ketua Tim Impresif & Bengkulu & 31 \\
AK & Onie Dian S & Ketua Tim Ekspresif & Temanggung & 30 \\
& Yansen AR & Pemusik (Pianis) & & \\
& Siregar & \multicolumn{3}{|l}{} \\
& Aris Kurniawan & \multicolumn{3}{|l}{} \\
\hline
\end{tabular}

\section{Proses Wawancara}

Wawancara dilakukan secara terpisah dengan menggunakan metode wawancara langsung pada bulan Januari dan Februari 2019 dengan lokasi di GKI Gejayan, kecuali narasumber LMS diwawancara di sebuah kafe di dekat GKI Gejayan.

Narasumber dibagi dalam dua kategori yakni:

A. Pemimpin jemaat, mereka adalah narasumber yang memiliki jabatan sebagai pendeta jemaat, pembina dan penatua, yakni: PL, HS, RN, dan AG.

B. Aktivis, yakni mereka yang memiliki jabatan di luar kategori A, yaitu: LMS, YO, OD, YS, dan AK.

\section{Pertanyaan Wawancara}

Kepada narasumber kategori A, saya menanyakan hal-hal berikut:

- Segala sesuatu yang terkait dengan proses penyusunan visi hingga proses dalam mewujudkannya.

- Aktivitas manajemen yang meliputi: perekrutan aktivis, pembinaan, pengelolaan dan pemeliharaan motivasi aktivis.

- Langkah-langkah yang dilakukan ketika menemui konflik, masalah, dan tantangan.

- Struktur organisasi.

- Apa saja yang menjadi wewenang, tugas, dan tanggung jawab narasumber.

Kepada narasumber kategori B, saya menanyakan hal-hal berikut:

- Apa yang menyebabkan narasumber tertarik bergabung sebagai aktivis?

- Bagaimana narasumber diperhatikan oleh pihak gereja sehingga motivasinya terjaga?

- Bagaimana narasumber juga mengajak orang lain bergabung?

- Apa saja yang menjadi tugas dan tanggung jawab narasumber?

Seluruh wawancara dibuatkan transkripsinya secara verbatim dan volume transkripsi total berjumlah 61 halaman A4. 


\section{Analisis Data}

Proses analisis data diawali dengan melakukan pengodean terhadap seluruh transkripsi. Setiap kategori narasumber memiliki kode yang berbeda.

1. Pengodean (Coding) Narasumber A

Untuk narasumber A, pengodean tahap pertama menghasilkan 31 kode. Namun setelah ditelaah lebih lanjut pada pengoden tahap kedua, jumlah kode menyusut menjadi 11 kode. Kesebelas kode tersebut adalah:

\begin{tabular}{|l|c|l|}
\hline \multicolumn{1}{|c|}{ Kode } & Singkatan & \multicolumn{1}{c|}{ Definisi } \\
\hline Latar Belakang & LBK & Data mengenai latar belakang narasumber. \\
\hline Organisasi & ORG & $\begin{array}{l}\text { Informasi tentang struktur organisasi di GKI } \\
\text { Gejayan. }\end{array}$ \\
\hline Perekrutan & REK & $\begin{array}{l}\text { Cara, prosedur, dan aktivitas yang dilakukan untuk } \\
\text { merekrut } \text { volunteer. }\end{array}$ \\
\hline Volunteerism & VLT & Prinsip volunteerism. \\
\hline $\begin{array}{l}\text { Tugas \& Tanggung } \\
\text { jawab }\end{array}$ & TDT & Tugas dan tanggung jawab narasumber. \\
\hline Kepemimpinan & PIM & $\begin{array}{l}\text { Informasi mengenai prinsip, konsep, dan gaya } \\
\text { kepemimpinan. }\end{array}$ \\
\hline Manajerial & MAN & $\begin{array}{l}\text { Informasi mengenai aktivitas manajerial yang } \\
\text { dilakukan. }\end{array}$ \\
\hline Pembentukan Visi & P-VISI & Proses pembentukan visi. \\
\hline $\begin{array}{l}\text { Tantangan dan } \\
\text { Masalah }\end{array}$ & TDM & $\begin{array}{l}\text { Berbagai tantangan dan masalah yang dialami oleh } \\
\text { narasumber. }\end{array}$ \\
\hline Mewujudkan Visi & M-VISI & $\begin{array}{l}\text { Langkah-langkah yang diambil dalam rangka } \\
\text { mewujudkan visi. }\end{array}$ \\
\hline Info Pemusik & IP & Informasi mengenai tipe dan kebutuhan pemusik. \\
\hline
\end{tabular}

2. Pengodean (Coding) Narasumber B

Untuk narasumber B pengodean tahap pertama menghasilkan 37 kode. Namun setelah ditelaah lebih lanjut pada pengoden tahap kedua, jumlah kode menyusut menjadi 13 kode. Ketiga belas kode tersebut adalah:

\begin{tabular}{|l|c|l|}
\hline \multicolumn{1}{|c|}{ Kode } & Singkatan & \multicolumn{1}{c|}{ Definisi } \\
\hline $\begin{array}{l}\text { Latar Belakang } \\
\text { Volunteer }\end{array}$ & LBV & $\begin{array}{l}\text { Berupa data latar belakang narasumber seperti } \\
\text { asal daerah dan pendidikan. }\end{array}$ \\
\hline Proses Bergabung & PG & $\begin{array}{l}\text { Cerita narasumber mengenai bergabungnya } \\
\text { yang bersangkutan menjadi aktivis. }\end{array}$ \\
\hline Pengorganisasian & ORG & Informasi tentang struktur organisasi. \\
\hline $\begin{array}{l}\text { Tugas dan Tanggung } \\
\text { jawab }\end{array}$ & TDT & $\begin{array}{l}\text { Informasi tentang tugas dan tanggung jawab } \\
\text { narasumber. }\end{array}$ \\
\hline Perekrutan Volunteer & PV & Cara bagaimana aktivis direkrut. \\
\hline Motivasi & MTV & Apa saja yang menjadi motivasi narasumber. \\
\hline Respons Pimpinan & RP & Respons pimpinan tentang suatu kondisi. \\
\hline
\end{tabular}




\begin{tabular}{|l|c|l|} 
Kepemimpinan & PIM & $\begin{array}{l}\text { Prinsip dan konsep kepemimpinan yang } \\
\text { muncul. }\end{array}$ \\
\hline Praktik Manajerial & PM & Aktivitas manajerial. \\
\hline Masalah dan Tantangan & MDT & $\begin{array}{l}\text { Informasi mengenai tantangan dan masalah } \\
\text { yang dihadapi narasumber. }\end{array}$ \\
\hline $\begin{array}{l}\text { Cara Mengatasi Konflik } \\
\text { (CMK) }\end{array}$ & CMK & Cara narasumber mengatasi konflik. \\
\hline Volunteerism $(\mathrm{VL})$ & VL & Prinsip volunteerism. \\
\hline Special Issue & SI & Hal-hal khusus yang disampaikan narasumber. \\
\hline
\end{tabular}

\section{HASIL DAN PEMBAHASAN}

\section{Lembaga Kepemimpinan GKI Gejayan}

GKI Gejayan adalah satu dari 200 lebih gereja yang ada di dalam lingkup Sinode Gereja Kristen Indonesia dan 1 dari 7 GKI yang ada di Klasis Yogyakarta (https:// www.gkiswjateng.org). Walaupun terhimpun dalam lingkup Klasis dan Sinode, setiap jemaat GKI adalah entitas mandiri. Mereka memiliki lembaga kepemimpinan yang relatif independen. Model lembaga kepemimpinan seperti itu disebut Presbiterian Sinodal. Dalam tingkat jemaat, lembaga pemimpin jemaat adalah Majelis Jemaat yang terdiri dari Pendeta (atau pendeta-pendeta) dan para Penatua (Presbiter). Pendeta adalah jabatan khusus yang diberikan kepada seseorang setelah memenuhi kriteria dan ditahbiskan/dilantik/diteguhkan untuk bertugas di satu jemaat. Sedangkan Penatua adalah anggota jemaat yang memenuhi syarat dan dipilih oleh jemaat untuk menjadi Penatua. (Tata Gereja GKI pasal 10).

Untuk menjalankan tugas pelayanan sebuah gereja, Majelis Jemaat dibantu oleh Komisi-komisi, Panitia atau Tim, Karyawan Gereja yang dibentuk dan diangkat oleh Majelis Jemaat.

\section{Struktur Organisasi}

Struktur organisasi di GKI Gejayan adalah sebagai berikut:

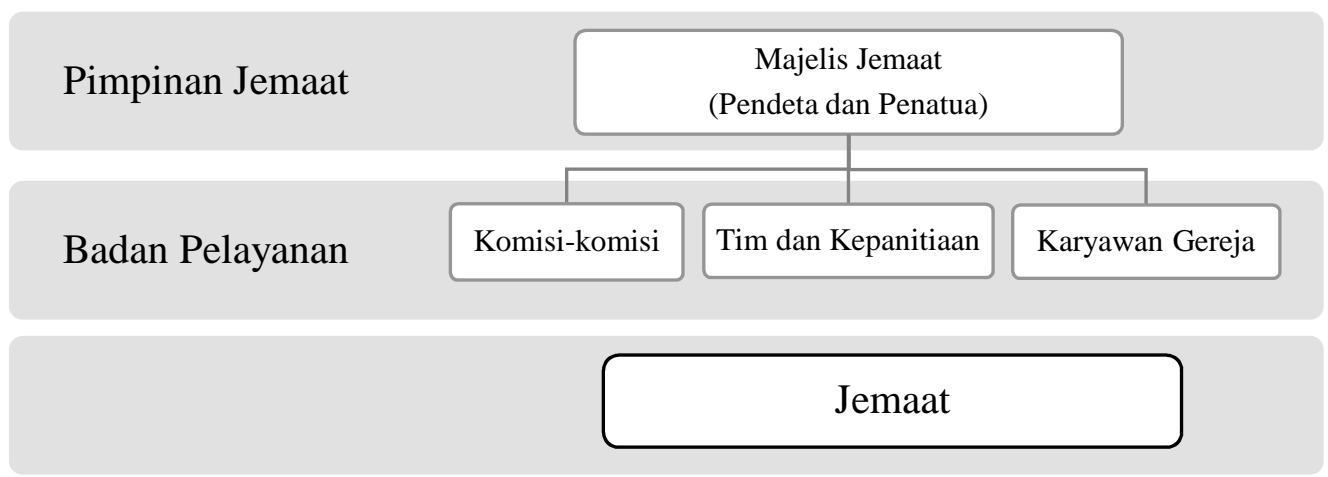

Kegiatan atau aktivitas sebuh organisasi gereja tidak melulu hanya peribadahan saja, namun juga di sana ada pembinaan jemaat, pelayanan sosial, kesaksian, dan manajemen maka, untuk mempermudah koordinasi di dalam kemajelisan, dibentuklah 
Koordinator Bidang sesuai dengan jenis pelayanannya. Di GKI Gejayan Majelis Jemaat membentuk enam bidang:

- Bidang I: Peribadahan, yakni bidang yang bertanggung jawab atas pelayanan ibadah jemaat di setiap Sabtu dan Minggu.

- Bidang II: Kesaksian dan Pelayanan, bertanggung jawab atas kegiatan kesaksian dan pelayanan sosial.

- Bidang III: Pembinaan, bertanggung jawab atas kegiatan pembinaan jemaat mulai dari jemaat anak-anak hingga jemaat lanjut usia.

- Bidang IV: Penata layanan, bertanggung jawab atas sarana dan prasarana fisik dan pengelolaan SDM (karyawan gereja).

- Bidang V: Pengajaran, bertanggung jawab atas pengajaran kepada jemaat.

- Bidang VI: Rencana Strategi GKI Gejayan, yang menyiapkan strategi pengembangan GKI Gejayan.

Di dalam penelitian ini yang menjadi objek penelitian adalah tim musik pengiring ibadah untuk menjelaskan fenomena kepemimpinan. Oleh karena itu, penulis tampilkan detail struktur organisasi terkait dengan pengelolaan tim musik sebagai berikut:

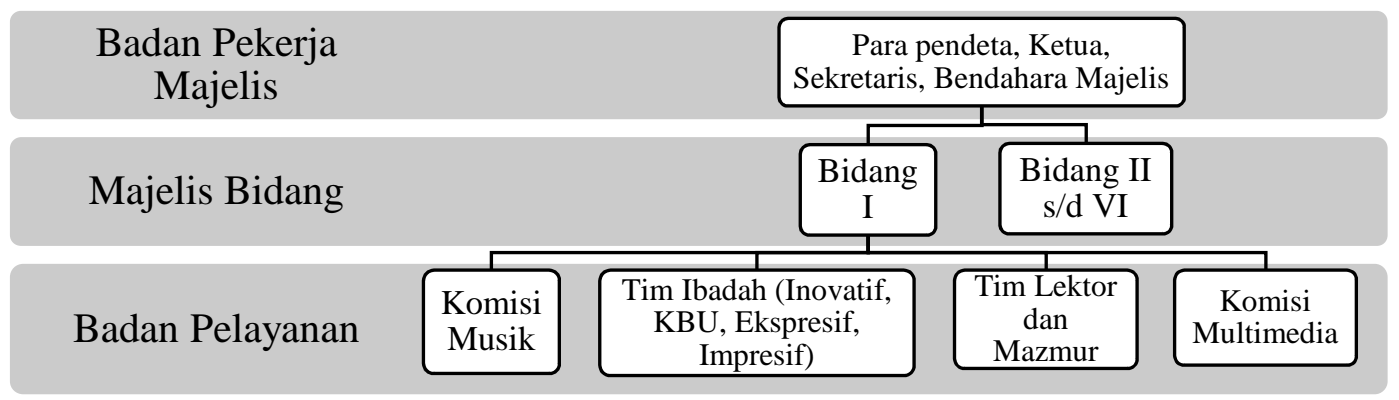

Di dalam struktur terdapat Komisi Musik yang memiliki tugas: merekrut pemusik, membina, dan menyalurkan para pemusik kepada tim-tim ibadah. Komisi Musik membentuk tim-tim musik untuk tim ibadah. Sedangkan tugas dan tanggung jawab Tim Ibadah akan dijelaskan secara detail berikut ini.

\section{Manajemen Ibadah di GKI Gejayan}

Ibadah Kristen bisa dikatakan mirip sebuah pagelaran teater. Di sana ada skenario yang disebut liturgi atau tata ibadah. Di sana ada juga para aktor: para penatua, pendeta, lektor (pembaca Alkitab), pemimpin pujian. Di sana ada juga pemusik yang mengiringi ibadah. Seluruh rangkaian acara dalam ibadah perlu dikelola agar ibadah berjalan lancar dan tertib sehingga jemaat dapat beribadah dengan khusyuk.

Tanggung jawab penyelenggaraan ibadah ada di tangan Majelis Jemaat sebagai Pemimpin Jemaat. Namun tentu dalam pelaksanaannya, Majelis perlu bantuan para aktivis. Mereka adalah:

1. Tim musik pengiring ibadah. Tim musik inilah yang akan mengiringi seluruh nyanyian yang dinyanyikan jemaat dalam ibadah (5 hingga 15 orang).

2. Pemimpin pujian/Song Leader. Mereka adalah yang memandu jemaat untuk bernyanyi (2 hingga 5 orang).

3. Pemandu liturgi (2 orang). 
4. Pembaca Alkitab (Lektor) dan pendaras Mazmur. Mereka yang bertugas untuk membaca Alkitab dan menyanyikan Mazmur (3 orang).

5. Pendeta yang berkhotbah (1 orang).

6. Tim Usher dan Pengedar kantong kolekte (10-20 orang).

Total jumlah orang yang terlibat di dalam sebuah ibadah bisa mencapai 40 orang.

Tentu saja kumpulan orang tersebut perlu dikelola agar setiap unsur dapat menjalankan tugasnya. Oleh karena itu, dibentuklah Tim Ibadah yang berfungsi sebagai Manajer Produksi. Tugas tim ini adalah:

1. Membuat daftar lagu yang akan dinyanyikan di dalam ibadah, bekerja sama dengan tim liturgi.

2. Membuat jadwal tim musik, pemandu pujian, dan pemandu liturgy, dan memastikan mereka semua siap melayani.

3. Berkoordinasi dengan tim lektor dan memastikan petugas lektor dan pemazmur siap melayani.

4. Berkoordinasi dengan tim multimedia mengenai kebutuhan tayangan di layar LCD berikut memastikan sound system dan lighting siap.

5. Menjadwalkan para usher dan pengedar kantong persembahan.

6. Memastikan ibadah berjalan sesuai dengan rencana.

GKI Gejayan memiliki 6 tim ibadah sesuai dengan kategori ibadah: Tim Ibadah (TI) Kebaktian Umum/KBU, TI-Ekspresif, TI-Impresif, TI-Inovatif, TI-Harmony, TIJoyfull. Susunan kepengurusan di dalam setiap tim adalah: Ketua, Sekretaris, Bendahara, Seksi Perlengkapan, Seksi Liturgi dan Musik, Seksi Konsumsi, Seksi Kostum, Seksi Usher.

Guna memastikan kualitas layanan, Tim Ibadah mengadakan evaluasi pada saat ibadah telah berakhir. Setiap masukan dan keluhan dari jemaat dibahas dalam evaluasi tersebut. Selain itu, Majelis Bidang I juga mengadakan rapat koordinasi setiap hari Kamis minggu pertama dengan semua Tim Ibadah dan Tim lainnya yang mendukung ibadah. Dengan demikian, kualitas layanan ibadah selalu terjaga.

\section{Volunteerism}

Organisasi GKI Gejayan digerakkan oleh para aktivis yang merupakan volunteer/relawan. Mereka adalah: para Penatua yang menjadi Majelas Jemaat, para Pengurus Komisi/Tim/Panitia, para pemusik, para pelatih, dan pembina. Mereka tidak mendapat gaji dari gereja, yang mendapat gaji hanyalah mereka yang bekerja penuh waktu yakni: para pendeta dan karyawan gereja. "Karena teologi GKI itu memang gerakan kaum awam", demikian ditegaskan narasumber PL.

Ram A. Cnaan (1996) sebagaimana dikutip Liu (2017) memberikan 4 dimensi volunteerism:

1. Dimensi Alamiah (motivasi volunteer harus datang dari dirinya sendiri, tanpa paksaan siapapun).

2. Dimensi Renumerasi (seorang volunteer tidak menerima penghargaan yang berwujud seperti uang).

3. Dimensi Struktur Aktivitas (kegiatan volunteer terkoordinasi dalam sebuah organisasi resmi).

4. Dimensi Identitas Penerima Layanan (volunteer melayani orang yang tidak dia kenal). 
Dari pengamatan yang penulis lakukan, keempat dimensi yang dipersyaratkan Cnaan di atas, ada dan ditemukan di dalam setiap aktivis di GKI Gejayan sehingga mereka pantas disebut volunteer: termotivasi oleh keinginan sendiri tanpa dipaksa, tidak menerima penghargaan dalam bentuk uang atau barang apapun, aktivitas mereka ada di dalam organisasi gereja, dan jemaat yang mereka layani sebagian besar tidak mereka kenal.

\section{Proses Mewujudkan Visi}

Sebagaimana sudah disampaikan pada bagian Pendahuluan di atas bahwa, GKI Gejayan saat ini mengelola 10 ibadah setiap minggunya yang membutuhkan volunteer tidak kurang dari 200 orang untuk melaksanakan ibadah-ibadah tersebut dan bahwa pertumbuhan jumlah ibadah (juga berarti pertumbuhan jumlah jemaat) adalah sebagai hasil dari terwujudnya visi GKI Gejayan, maka yang penulis teliti untuk diketahui jawabannya adalah bagaimana GKI Gejayan mewujudkan visi tersebut.

Data yang penulis peroleh dari wawancara yang sudah penulis analisis mengatakan bahwa sebelum menetapkan visi atau ke arah mana organisasi gereja akan melangkah, setiap orang yang ada di dalam organisasi harus memahami terlebih dahulu karakter dan keberadaan organisasi. Melakukan riset adalah cara untuk mengetahui ada di mana posisi sebuah organisasi dan itu dilakukan oleh Pendeta Lie (narasumber PL) pada tahun 2002 yang menghasilkan kesimpulan bahwa:

- GKI Gejayan adalah gereja yang 60-70 persen jemaat yang beribadah adalah kalangan muda dengan umur di bawah 30 tahun yang merupakan mahasiswa pendatang dari berbagai daerah.

- Jemaat tersebut memiliki keragaman (diversities) kebutuhan, termasuk keragaman bentuk ibadah (sebagaimana sudah dijelaskan di bagian Pendahuluan).

Dengan karakter yang demikian GKI Gejayan tidak bisa berdiam diri. GKI Gejayan harus berubah dan beradaptasi dengan tantangan yang dihadapinya. GKI Gejayan harus menjadi jemaat yang terbuka yang mau menerima jemaat dengan berbagai latar belakang dan kebutuhan, dan juga harus rela menjadi gereja "training center" karena sebagian besar jemaatnya adalah mahasiswa yang keberadaannya di Yogyakarta hanya sementara saja selama mereka menjalani pendidikan. PL selaku pendeta jemaat menyadari ini, namun untuk melakukan perubahan dia tidak bisa sendiri karena GKI menganut sistem Presbiterial Sinodal. Setiap keputusan harus diambil melalui forum Majelis Jemaat di mana di situ ada para penatua.

\section{Menanamkan Nilai}

PL selaku pendeta perlu memberikan keyakinan kepada para koleganya para penatua dalam kemajelisan mengenai pentingnya GKI Gejayan untuk berubah menjadi gereja yang terbuka. Nilai-nilai ini secara sabar dikomunikasikan dan didialogkan. Kekuasaan yang PL gunakan dalam memengaruhi, tentunya bukan kekuasaan yang menekan (coercieve power) namun lebih kepada Referent Power atau Charisma Power. Dibutuhkan waktu hampir 2 tahun untuk meyakinkan seluruh pimpinan jemaat sehingga mereka benar-benar yakin dan mendukung visi untuk berubah. 


\section{Membangun Tim Inti}

Langkah berikutnya dalam membuat visi perubahan menjadi nyata adalah membangun sebuah tim inti. Tim ini adalah para aktivis atau volunteer yang direkrut dari kalangan jemaat. Proses penanaman nilai yang dilakukan PL kepada koleganya para penatua, dilakukan pula kepada beberapa orang yang direkrut sebagai tim inti/tokoh kunci. Tim inti ini adalah:

a. Ibu Hanna dan Pak Suwarta yang membantu dalam pembentukan tim ibadah impresif.

b. Pak Tedjo yang membantu dalam pembentukan tim ibadah ekspresif.

c. Pak Petrus Matrudi (menurut narasumber AK) yang membantu di tim ibadah KBU.

d. Pak Ricky (narasumber RN) yang saat itu aktivis di Komisi Musik.

Selain itu masih ada lagi tim inti di bidang lain di luar peribadahan yang tidak menjadi objek penelitian penulis.

Melibatkan sebanyak mungkin jemaat sebagai aktivis menjadi prinsip kepemimpinan PL. Prinsip ini sejalan dengan model kepemimpinan transformatif. Dalam kharismanya sebagai pendeta, PL memberi perhatian kepada setiap individu aktivis sehingga mereka benar-benar merasa terlibat dan diberi tanggung jawab dalam melakukan perubahan. PL juga adalah seorang pemimpin yang inspiratif yang dengan sabar menanamkan nilai-nilai dan visi perubahan GKI Gejayan. Sebagaimana dirasakan oleh seorang aktivis LM yang menyatakan bahwa PL adalah seorang konseptor yang memberi ruang bagi anak muda untuk berkreasi. Demikian juga dalam pendelegasian dikatakan bahwa:

"Jadi Pak Paulus itu saya lihat punya konsep dibikin seperti apa, disampaikan ke tim ibadah misalnya atau ke komisi. Nanti komisi yang menggodok gitu ya.." (LMS, 29 tahun)

\section{Merekrut Para Aktivis}

GKI Gejayan bergerak karena para aktivis yang notabene adalah volunteer yang bergerak. Para aktivis inilah pemeran utamanya, para pendeta dan karyawan gereja justru berada di posisi sebagai pendukung. Dari manakah datangnya para aktivis? Tentu saja sumber utama para aktivis ini adalah jemaat yang hadir di dalam ibadah Sabtu dan Minggu dan juga jemaat yang hadir di ibadah remaja dan pemuda. Bagaimanakah mereka tertarik menjadi aktivis?

\section{a. Daya Tarik GKI Gejayan}

Dari jawaban narasumber yang penulis wawancarai, berikut ini adalah daya tarik GKI Gejayan yang membuat mereka tertarik bergabung menjadi aktivis:

1. Terdapat banyak pilihan ibadah (diungkapkan LMS, OD).

2. Musik ibadahnya bervariasi terutama mengakomodasi musik kontemporer (dengan iringan full band) (diungkapkan AK, LMS, AG).

3. Tersedia banyak fasilitas (AK, OD).

4. Menemukan banyak teman.

"Nah, komunitas di sini itu macem-macem, nah kita misalnya (suku)

Dayak nih.. di sini buaanyaak banget Dayaknya.. Begitu ketemu o..

banyak saudara, banyak keluarga.." (OD, asal Palangkaraya Kalteng).

5. Terbuka dan fleksibel. "Kita mau eksplor macem-macem di sini ada." (OD) dan "pemimpin gerejanya juga memang apa ya.. welcome." (YS, asal Bengkulu). 
Bagi mahasiswa dengan bakat musik, GKI Gejayan memiliki daya tarik tersendiri karena di sini mereka seakan bisa mengekspresikan diri dengan bergabung pada salah satu tim musik. Sedangkan bagi mahasiswa pendatang, dari mana pun daerahnya, akan merasa sangat diterima di GKI Gejayan.

Dengan karakternya sebagai gereja yang terbuka, mau melayani siapa saja yang datang, GKI Gejayan menjadi magnet bagi mahasiswa pendatang yang sedang berkuliah di Yogyakarta. Secara tidak sengaja, telah tercipta loop yang menciptakan amplifikasi: gereja yang ramah terbuka $\rightarrow$ menarik banyak jemaat $\rightarrow$ jemaat merasa diterima $\rightarrow$ menjadi aktivis $\rightarrow$ membuat gereja yang ramah terbuka.

\section{b. Proses Perekrutan Aktivis}

Meskipun memiliki daya tarik, tidak serta merta jemaat yang tertarik akan langsung memutuskan untuk bergabung sebagai aktivis. Proses rekrutmen menjadi proses berikutnya yang sangat menentukan. GKI Gejayan menjalankan berbagai program untuk merekrut para aktivis:

1. Gejayan Fair, adalah sebuah pameran pelayanan di mana setiap Badan Pelayanan (Komisi, Tim, dan Panitia) memamerkan layanannya dan mengajak jemaat untuk bergabung. Kegiatan ini dilakukan setiap enam bulan sekali.

2. Tantangan melalui khotbah. PL selaku pendeta jemaat sering mengingatkan soal pelayanan dan memberi tantangan "Satu Orang Satu Pelayanan", maksudnya adalah setiap jemaat didorong untuk menjadi aktivis minimal di satu pelayanan.

3. Menggerakkan seluruh unsur: Penatua, Pendeta, dan para aktivis.

“.. jadi semua lini bergerak. Ndak boleh hanya mengandalkan anak-anak saja, ya nggak bisa.. mengandalkan pemimpin ya semua bergerak..” (PL)

\section{Memelihara Motivasi}

Aktivis yang saya wawancarai sebagai narasumber telah aktif di GKI Gejayan sudah cukup lama. RN misalnya, yang telah aktif di Komisi Musik di tahun 2000 (bahkan sebelum GKI Gejayan belum menjadi jemaat mandiri, baru berstatus Pos Kebaktian milik GKI Ngupasan) hingga kini (2019) menjabat sebagai Penatua. Atau AK yang telah aktif sejak mahasiswa bahkan kini telah menjadi dokter dan berkeluarga. Apa yang menyebabkan mereka memiliki motivasi yang selalu terjaga? Jawaban-jawaban yang terkumpul sebagai berikut.

a. Panggilan untuk melayani.

Tema ini memang yang selalu dikhotbahkan dalam rangka merekrut volunteer. Bahwa sebagai jemaat Tuhan, mereka memiliki "kewajiban" untuk melayani. Ini sepertinya bisa digolongkan pada fungsi "Values" dalam teori VFI namun, agak sulit digolongkan apakah ini motivasi intrinsic atau extrinsic seperti yang dimaksud SDT. Saya lebih memilih untuk menyebutnya "Motivasi Spiritual (MS)" karena menyangkut sistem kepercayaan atau iman seseorang. MS tidak bisa dikatakan intrinsik murni karena di sana ada tersirat "kewajiban", ibarat seorang anak ketika melakukan kebaikan untuk orang tuanya bisa bersifat intrinsik atau ekstrinsik. Bagi anak yang benar-benar mengasihi orang tuanya, pekerjaan apapun yang bisa membuat senang orang tuanya akan dilakukan dengan sepenuh hati. Demikian juga bagi seorang aktivis, ketika dia benar-benar menghayati 
panggilannya untuk melayani maka, kegiatan pelayanan apapun akan dilakukan dengan penuh suka cita ("joy"). Itulah motivasi instrinsik.

b. "Melayani di sini itu memberi rasa nyaman." (OD),

"Saya di sini ketemu banyak orang dari yang berlatar belakang musik" (AK),

"gak dapet apa-apa ya secara materi, cuma ada proses, pembinaan.." (LMS)

Jawaban-jawaban tersebut seperti menyiratkan bahwa, motivasi pelayanan disebabkan adanya benefit yang volunteer dapatkan walaupun wujudnya bukan berupa uang. Benefit itu antara lain: rasa nyaman, mendapat perhatian, merasa diberi kepercayaan, bisa berekspresi, bahkan untuk para pemusik bisa tampil bermain musik adalah sebuah reward yang berharga. Seperti yang dialami oleh pemusik di tim impresif yang beragama nonKristen, yang mereka peroleh adalah kesempatan bermain dalam orkestra yang tidak mereka temukan di tempat lain.

Memelihara motivasi para aktivis adalah kunci yang membawa GKI Gejayan terus berkembang. Secara spiritual para aktivis ini terus dijaga motivasinya melalui kegiatan seperti pelatihan, retreat aktivis, fellowship. Namun paralel dengan itu, para pemimpin GKI Gejayan juga memperhatikan kebutuhan para aktivis. Seperti misalnya pemusik diberi pelatihan-pelatihan atau para aktivis diberi wewenang untuk mengajukan program kerja. Dan lebih dari itu, para pemimpin jemaat selalu menjaga komunikasi dengan para aktivis dan memberi perhatian secara personal.

\section{Kepemimpinan yang Sukses Mewujudkan Visi}

Dari analisis yang penulis lakukan terhadap hasil wawancara, penulis mendapat gambaran model kepemimpinan yang terjadi di GKI Gejayan sebagai berikut.

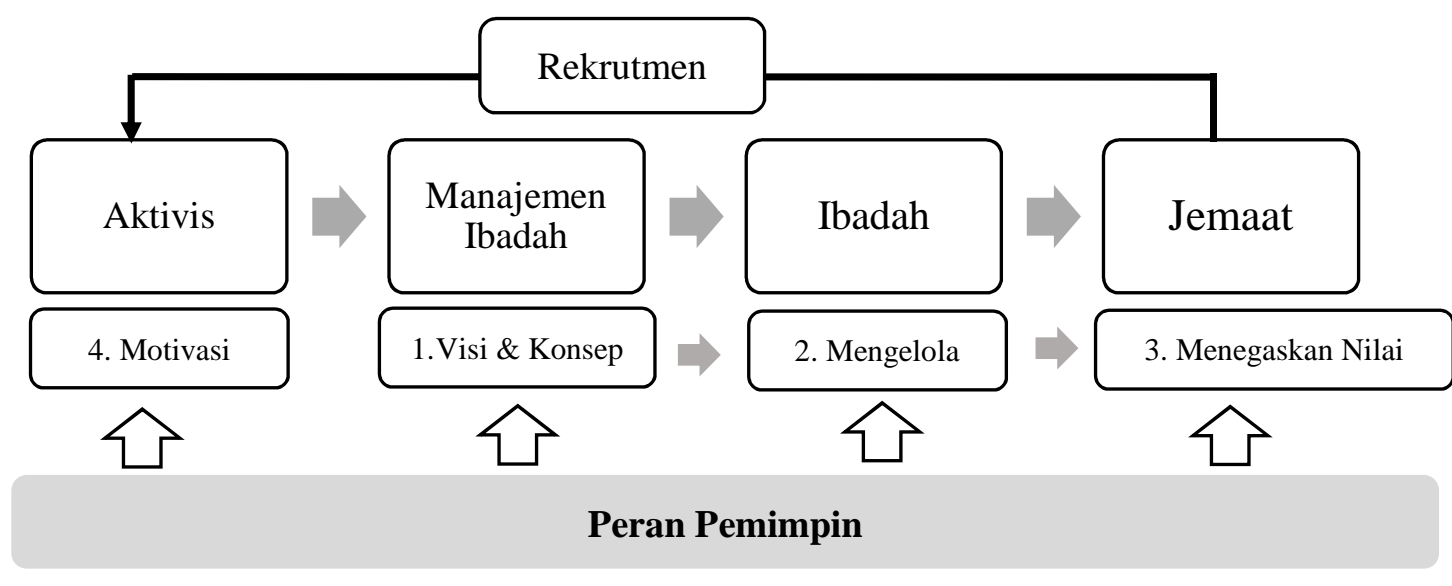

Gambar 4. Model Kepemimpinan yang Hadir

Penulis menyebutnya Kepemimpinan yang Hadir (Attending Leadership) yaitu kepemimpinan yang selalu hadir di dalam setiap proses mewujudkan visi:

1. Penyusunan Visi dan Konsep

- Pemimpin memahami situasi di mana dia berada dan menentukan arah ke mana dia akan membawa organisasinya melangkah.

- Pemimpin membangun tim dan membuat konsep tentang bagaimana visi itu akan diwujudkan.

2. Mengelola 
- Pemimpin melakukan delegasi kepada tim inti dan aktivis yang dia percayai sehingga tanggung jawab untuk mewujudkan visi tidak hanya bertumpu padanya.

- Pemimpin melakukan quality control dan segera memberi arahan jika ada penyimpangan.

3. Menegaskan Nilai

- Komunikasi dengan jemaat (anggota/pengikut) mengenai visi, konsep, dan rencana kerja sehingga jemaat memahami nilai-nilai yang sedang dikembangkan.

- Mendorong jemaat untuk ikut ambil bagian dalam mewujudkan visi.

4. Menjaga Motivasi

- Menerapkan pemimpin yang transformatif; memberikan perhatian personal kepada para aktivis dengan berbagai cara seperti: komunikasi dan dialog, memenuhi kebutuhan aktivis.

- Menyelesaikan konflik yang terjadi dengan segera saat skala konflik masih kecil.

- Memberi kepercayaan kepada para aktivis.

Di atas semua itu, diperlukan kesabaran dan determinasi dari pemimpin karena proses mewujudkan visi bukanlah sesuatu yang instan. PL membutuhkan waktu 2 tahun agar seluruh pemimpin jemaat memahami perlunya perubahan sehingga akhirnya konsep ibadah ekspresif dan impresif terwujud. Kebanyakan pemimpin sering kurang cukup sabar dan telaten terutama di tahap-tahap awal proses yang akhirnya berakibat visi gagal diwujudkan.

\section{KESIMPULAN}

Memahami karakter organisasi adalah awal dari seluruh perjalanan sebuah organisasi. Dengan pemahaman yang benar maka, kita bisa tahu keberadaan kita ada di mana sehingga kita bisa menentukan ke arah mana perjalanan berikutnya. Ini adalah peran pemimpin yang pertama. Selanjutnya, pemimpin yang sukses adalah pemimpin yang dapat membangun tim yang solid yang memiliki visi yang sama. Dan pada akhirnya, kesabaran dan determinasi akan menentukan kesuksesan seorang pemimpin. Itulah kesimpulan mengenai model kepemimpinan yang telah membawa GKI Gejayan mencapai visinya.

Penelitian ini hanyalah terbatas pada pengelolaan tim musik pengiring ibadah di GKI Gejayan padahal masih ada pelayanan-pelayanan lain yang belum penulis teliti. Oleh karena itu, penelitian ini masih bisa dikembangkan misalnya, melalui pendekatan dampak sosial dari pembinaan-pembinaan yang dilakukan oleh GKI Gejayan.

\section{KEPUSTAKAAN}

Barrow, Jeffrey C. 1977. The Variables of Leadership: A Review and Conceptual Framework. Academy of Management Review Journal. April 1997.

Bass, Bernard M. 1990. From Transactional to Transformational Leadership: Learning to Share the Vision. Organizational Dynamics, Vol. 18, No. 3, 1990, pp. 19-31.

Chacón, Fernando, Gema Gutiérrez, Verónica Sauto, María Luisa Vecina and Alfonso Pérez. 2017. "Volunteer Functions Inventory: A systematic review". Psicothema 2017, Vol. 29, No. 3, 306-316. 
Clary, E. G., Snyder, M., Ridge, R. D., Copeland, J., Stukas, A. A., Haugen, J., \& Miene, P. 1998. Understanding and assessing the motivations of volunteers: A functional approach. Journal of Personality and Social Psychology, 74, 1516-1530.

Deci, Edward L., Richard M. Ryan. 2000. Intrinsic and Extrinsic Motivations: Classic Definitions and New Directions. Contemporary Educational Psychology 25, 5467.

Gardner, John W. 1990. The Task of Leadership. In John Gardner's “On Leadership”. New York USA. The Free Press.

Kotter, John P. 2001. What Leaders Really Do. Best of Harvard Business Review December 2001. Harvard Business School Publishing Coorporation.

Liu, E. S. C., Constance W. L. Ching, and Joseph Wu. 2017. Who is a volunteer? A cultural and temporal exploration of volunteerism. Journal of Human Behavior in the Social Environment 2017, Vol. 27, No. 6, 530-545.

Lunenberg, Fred C. 2011. Expectancy Theory of Motivation: Motivating by Altering Expectations. International Journal of Management, Business, and Administration Volume 15, Number 1, 2011.

Burke, Rory dan Steven Barron. 2014. Project Management Leadership: Building Creative Teams-Second Ed.West Sussex UK. John Wiley \& Sons, Ltd.

David, Fred R., dan Forest R. David. 2017. Strategic Management: Concepts and Cases. Essex-England. Pearson Education Limited.

King, Sarah N., David J. Altman, Rober J. Lee. 2011. Discovering the Leader in You. San Fransisco USA. Jossey-Bass A Wiley Imprint.

Maslow, Abraham H. 1954. Motivation and Personality. Harper and Row, Publisher.

Sinode GKI. Tata Gereja GKI. Sinode GKI.

Lie, Paulus. https://gkigejayan.or.id/. Diakses tanggal 8 Juni 2019 jam 22.54 WIB

GKI Sinode Wilayah Jawa Tengah (SW-Jateng). https://www.gkiswjateng.org/churches/detail/gki-gejayan. Diakses tanggal 8 Juni 2019 jam 22.55 WIB.

https://id.wikipedia.org/wiki/Wilayah_pelayanan_Gereja_Kristen_Indonesia 